\title{
A perspectiva da sustentabilidade no campo da saúde
}

\section{Perspectives on health and sustainability}

Resenha escrita por Severino Soares Agra Filho

Prof. Dr. do Departamento de Engenharia Ambiental da Universidade Federal da Bahia, Salvador, BA, Brasil End. Eletrônico: severino@ufba.br

doi:10.18472/SustDeb.v8n1.2017.19942

SOUZA, Cezarina Maria Nobre et al. Saneamento: promoção da saúde, qualidade de vida e sustentabilidade ambiental. Rio de Janeiro: Fiocruz, 2015. ISBN: 978-85-7541-470-5

O livro de autoria de quatro pesquisadores doutores em saúde pública, de distintas formações profissionais, faz parte da coleção Temas em Saúde da editora Fiocruz. Dois especialistas possuem formação em engenharia sanitária (profa. Dra. Cezarina Maria Nobre Souza/IFPA e prof. Phd Luiz Roberto Santos Moraes/UFBA), um em engenharia de minas (André Monteiro Costa/pesquisador da Fiocruz) e o outro em história (Carlos Machado de Freitas/ pesquisador da Fiocruz). Assim, o seu conteúdo apresenta a singularidade propícia e a coerência conceitual indispensável para a abordagem de um tema interdisciplinar.

A partir da contextualização da realidade social, sua crescente complexidade e suas implicações na precária qualidade de vida da sociedade - as quais consideram uma flagrante violação aos direitos humanos - os autores destacam que, para a superação dessa condição deplorável, é imprenscindível o devido reconhecimento e compreensão das relações interdependentes da tríade: modelo de desenvolvimento, ambiente e saúde. Nessa perspectiva, os autores consideram fundamental reformular o papel do saneamento como um dos fatores determinantes na mediação dessas relações, o que exigirá um novo olhar, a sua proposição como política pública e social.

Ao expor tal proposição, os autores apresentam como um eixo condutor os conceitos de promoção da saúde e de sustentabilidade ambiental em oposição à visão convencional preventista, e ainda hegemônica, que prioriza as ações de saneamento como barreiras para evitar as doenças. Para o desenvolvimento dessa proposição e o necessário esclarecimento sobre a promoção da saúde, que trabalha com "a busca de soluções tecnológicas e de gestão sociocultural" a partir da compreensão "das pessoas, do modo como vivem, de sua cultura e sua inserção social", os autores apresentam um escopo didático abordando: os antecedentes históricos das relações entre saneamento saúde e ambiente, a evolução do saneamento no Brasil, as características que evidenciam a mudança do foco preventista para o enfoque na promoção da saúde e na sustentabilidade ambiental; e propõem elementos para orientar essa transição. 
$\mathrm{Na}$ abordagem histórica, apresentam resumidamente o "surgimento do saneamento no âmbito comunitário e sua passagem para a esfera pública", remontam às mudanças nos diversos períodos da sociedade e suas implicações no meio ambiente e no modo de vida das pessoas. Relatam como a intensificação das interações do homem com o ambiente foi propícia para aparecimento de doenças, focos de vetores e de dejetos sem a adequada destinação e para a criação de medidas para sanear essa situação. Pontuam a Revolução Industrial e o aumento dos problemas de qualidade de vida urbana, o que vai evidenciar a relação entre as doenças e as condições ambientais, o saneamento em particular.

Os autores assinalam as contribuições de Hipócrates, Edwin Chadwick e John Snow na formulação de processos saúde-doença relacionados à concepção preventista do saneamento e na sua consolidação como uma preocupação pública e ação de Estado. Esclarecem que no higienismo o "objetivo era combater os miasmas causadores de doença". A concepção preventista tem como base o agente biológico presente, responsável pela transmissão de doenças no ambiente; o objetivo do saneamento seria afastar o agente da doença e os fatores ambientais, ou se interpor em sua ação. $O$ saneamento seria nesse caso "uma intervenção de engenharia em determinado espaço físico visando higienizar o ambiente e obstruir a transmissão de doenças". Eles concluem que persistem "em ambas as concepções o conceito de saúde como oposta a condição de doença".

$\mathrm{Na}$ abordagen sobre a mudança do foco de saneamento, os autores refletem sobre os fundamentos que caracterizam a concepção preventista e a concepção proposta de promoção da saúde e o que as diferecia. Esclarecem que a concepção preventista, embora necessária, é insuficiente para atender a abrangência desejável da promoção da saúde, pois seu enfoque restringe "o saneamento a uma intervenção ambiental exclusiva da engenharia, cabendo-lhe apenas implantar sistemas" visando "manter o ambiente limpo e salubre e a melhoria dos indicadores epidemiológicos".

Na explanação referente ao Brasil, os autores descrevem uma cronologia para as diferentes etapas históricas e as respectivas características das visões das políticas de saneamento desenvolvidas, apresentam uma breve estatística sobre a evolução das prestações de serviços e as condições que foram alcançadas a partir destes, o que é complementado pela exposição de dados comparativos de outros países. Salientam os diversos modelos experimentados bem como as fragilidades nacionais reveladas nas taxas de internações associadas à carência de saneamento. Esses resultados desfavoráveis são, segundo os autores, evidências indiscutíveis da inadequação da política de saneamento adotada, que está associada à visão preventista.

Aqui merecem destaques duas informações relevantes e de certa forma surpreendentes para os leitores em geral. A primeira é sobre o recente reconhecimento do saneamento como direito social e responsabilidade do Estado. Somente em 2010 a ONU declara o "acesso à água limpa e segura e o esgotamento sanitário adequado como direito humano essencial". A segunda informação é o Estado brasileiro ter feito esse reconhecimento em 2006, anteriormente ao da ONU, ao determinar, no Sistema Nacional de Segurança Alimentar e Nutricional (SISAN), que "a alimentação adequada, incluindo-se a água, é um direito fundamental do ser humano [...]."

Em contraponto e como um subsídio esclarecedor, os autores caracterizam em seguida a origem, os princípios e conceitos, bem como as vertentes de atuação da linha da promoção da saúde. Abordam "as práticas e tendências do saneamento" enfatizando a necessidade de se atuar com a visão de um "sistema e serviço integrado e sustentável" na gestão dos resíduos sólidos bem como de se fazer a devida adoção das tecnologias apropriadas no seu manejo. O propósito seria alinhar o saneamento ao universo da promoção da saúde, que, embora observada em alguns textos institucionais, não atinge as estratégias e práticas de atuação, que persistem sob a visão convencional. Os autores argumentam com elementos conceituais para caracterizarem a concepção da promoção da saúde associada à qualidade de vida com sustentabilidade ambiental e seus horizontes.

Uma questão a considerar seria a pertinência da perspectica da sustentabilidade com a promoção da saúde. O conceito de sustentabilidade, oriundo da adjetivação desenvolvimento sustentável, remete à expectativa de uma condição da qualidade desejável e duradoura, ou ireversível. Assim, o princípio da promoção da saúde seria a incorporação do princípio sustentabilidade no horizonte pleno da saúde 
(RATTNER, 2009). Diante das controvérsias e, em geral, da visão reducionista da adoção do conceito de sustentabilidade, os autores trazem uma contribuição relevante e oportuna na sua inserção no campo da saúde, enfatizando a visão cultural e abrangente indispensável na aplicação desse conceito (ACSELRAD, 1997).

As ideias defendidas convergem didaticamente para uma conclusão com a apresentação das proposições de um saneamento orientado nesse sentido. Frisam que o imperativo de uma transição implica a necessidade de desdobramentos institucionais e culturais que induzam procedimentos consistentes com o novo olhar desejado e um novo locus de atuação. São bem-sucedidos o delineamento e os esclarecimentos apresentados sobre o papel do saneamento na mediação da qualidade de vida e as suas vinculações, subordinações e suas interfaces com outras dimensões e políticas socias.

De um modo geral, tanto os profissionais do saneamento, os engenheiros sanitaristas e ambientais em particular, quanto os de saúde pública em geral foram brindados com uma publicação oportuna e de suma importância como exercício de reflexão conceitual. Merece destaque ainda a linguagem didática e acessível ao grande público utilizada no texto. O livro propicia, portanto, um valioso balizamento teórico para o norteamento de formulação de políticas e programas governamentais, assim como para o redirecionamento daqueles já vigentes, ressaltando que a aplicação da concepção proposta, exigirá um esforço contra hegemônico e determinação das instâncias políticas para o enfretamento dos desafios tecnológicos e culturais requeridos para sua efetivação.

\section{Referências}

ACSELRAD, H. (1997). Sustentabilidade e democracia. Revista Proposta, n. 71, Rio de Janeiro, fevereiro de 1997.

RATTNER, H. Meio ambiente, saúde e desenvolvimento sustentável. Ciência \& saúde coletiva, vol.14 no.6 Rio de Janeiro Dec. 2009. 